\title{
Produtos de pescado elaborados com resíduos de arrasto: análise físico-química, microbiológica e toxicológica
}

[Fish products made from trawl fishery waste: physical, chemical, microbiologic, and toxicological analysis]

D.S. Ribeiro ${ }^{1}$, F.A.A. Calixto ${ }^{2}$, J.L.B. Guimarães ${ }^{1}$, M. Aronovich ${ }^{3}$, L.A.M. Keller ${ }^{4}$, E.F.M. Mesquita ${ }^{4}$

${ }^{1}$ Aluno de pós-graduação - Universidade Federal Fluminense - UFF - Niterói, RJ

${ }^{2}$ Fundação Instituto de Pesca do Estado do Rio de Janeiro - FIPERJ

${ }^{3}$ Empresa de Pesquisa Agropecuária do Estado do Rio de Janeiro - Pesagro - Niterói, RJ

${ }^{4}$ Universidade Federal Fluminense - UFF - Niterói, RJ

\begin{abstract}
RESUMO
\end{abstract}
$\mathrm{Na}$ pesca de arrasto, são inúmeras as espécies de peixe capturadas acidentalmente, compostas, em sua maioria, de espécimes de pequeno tamanho e baixo valor comercial, os quais recebem o nome de rejeito de pesca. O presente trabalho teve como objetivo o desenvolvimento de dois produtos, almôndega e quibe de peixe, tendo como matéria- prima espécies consideradas capturas acidentais na modalidade de pesca de arrasto realizada no litoral do Rio de Janeiro. A identificação taxonômica das espécies teve como resultado as espécies pargo (Pagrus pagrus), castanha (Umbrina sp.), olho-de-cão (Priacanthus arenatus), congro-negro (Conger sp.), congro-rosa (Genypterus brasiliensis) e peixe-sapo (Lophius gastrophysus). A matéria seca percentual na polpa foi de $31,20 \pm 1,30 \%$, no quibe e na almôndega crus; os valores foram de 37,90 $\pm 1,10$ e $32,10 \pm 1,10$, respectivamente. Nos produtos assados, os resultados foram $33,40 \pm 1,20$ para o quibe e $34,20 \pm 1,00$ para a almôndega. Os teores de cinzas na polpa foram 1,5\% para o

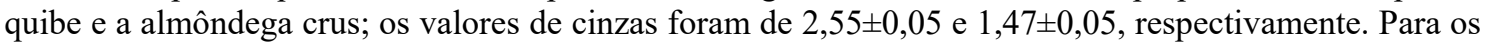
produtos assados, os resultados foram $1,87 \pm 0,05$ para o quibe e $1,92 \pm 0,05$ para a almôndega. Os teores de lipídeos aferidos na polpa foram de $4,80 \pm 0,30 \%$. Com relação ao quibe e à almôndega crus, o percentual

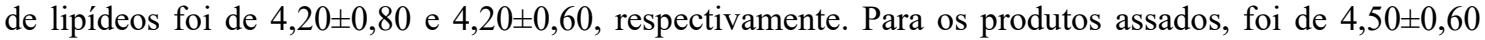

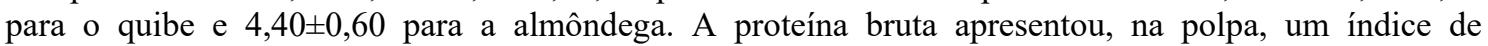

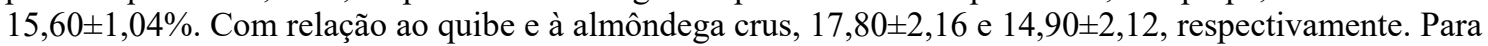
os produtos assados, 15,10 $\pm 2,10 \mathrm{em}$ ambos. Os compostos nitrogenados solúveis, formadores do NNP, apresentaram valores de $285 \mathrm{mg} \mathrm{NNP} / 100 \mathrm{~g}$ de polpa de pescado crua, $291 \mathrm{mg} \mathrm{NNP} / 100 \mathrm{~g}$ no quibe cru e $294 \mathrm{mg} \mathrm{NNP} / 100 \mathrm{~g}$ na almôndega crua. Os resultados da contagem total de psicrotróficos mantiveram-se abaixo de $\log 7,0 \mathrm{UFC} / \mathrm{g}$, para contagem padrão em placas de microrganismos aeróbicos. Não foi constatada a presença de coliformes fecais Salmonella e Staphylococcus aureus. Também não foram detectados níveis de histamina e compostos à base de enxofre nas amostras.

Palavras-chave: arrasto, tecnologia do pescado, novos produtos, inocuidade

\begin{abstract}
Seafood products represent an important source of proteins and minerals as well as polyunsaturated fatty acids. However, its consumption in Brazil is very low in comparison to other kinds of meat. This may due to lack of skill in its preparation, making immensurable the importance of the search for new ways to market it, such as ready-made or semi-ready to serve products. The trawl fishery method often accidentally captures a variety of species, composed basically of low commercial value and size. Such catches are called "second-hand catch". With this in mind, this paper has as its main objective de development of two products: fish meatball and kibe, using what is considered accidental catches in the
\end{abstract}

Recebido em 19 de fevereiro de 2016

Aceito em 15 de março de 2017

E-mail: nda_diego@yahoo.com 
trawl fishery industry done on Rio de Janeiro's offshore as the raw material. The taxonomic identification of the species resulted in the species, Red porgy (Pagrus pagrus), Argentine croaker (Umbrina sp.), Atlantic bigeye (Priacanthus arenatus), Black cusk-eel (Conger sp.), Cusk-eel (Genypterus brasiliensis) and Blackfin goosefish (Lophius gastrophysus). The dry material of the raw product was $31.20 \pm 1.30 \%$, in

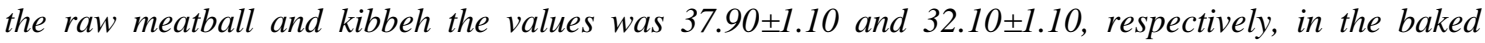
product the results was $33.40 \pm 1.20$ and $34.20 \pm 1.00$ (kibbeh and meatball). The ash content in the pulp was $1.5 \%$, for the raw kibbeh and meatball, the amounts of ash were $2.55 \pm 0.05$ and $1.47 \pm 0.05$, respectively. For baked goods results were $1.87 \pm 0.05$ for the kibbeh and $1.92 \pm 0.05$ for the meatball. The measured lipid levels in the pulp was $4.80 \pm 0.30 \%$. In respect, raw kibbeh and meatball, the percentage of lipids were $4.20 \pm 0.80$ and $4.20 \pm 0.60$, respectively. For baked goods was $4.50 \pm 0.60$ for the kibbeh and $4.40 \pm 0.60$ for the meatball. The protein level presented in the raw material was $15.60 \pm 1.04 \%$, to the raw kibbeh and meatball was $17.80 \pm 2.16$ and $14.90 \pm 2.12$ and for the baked goods $15.10 \pm 2.10$ both. Soluble nitrogen compounds shows values of $285 \mathrm{mg} / 100 \mathrm{~g}$ in the raw material, in the kibbeh $\mathrm{NNP} 291 \mathrm{mg} / 100 \mathrm{~g}$ and the meatball NNP $294 \mathrm{mg} / 100 \mathrm{~g}$. The results of the total count of psychotropic remained below $7.0 \mathrm{log}$ $\mathrm{CFU} / \mathrm{g}$, for standard count of aerobic microorganism plates. Fecal coliform bacteria, Salmonella, and Staphylococcus aureus were not present. The levels of histamine and sulfur basic compounds $\left(\mathrm{H}_{2} \mathrm{~S}\right)$ were not detected in the samples.

Keywords: trawl fishery, seafood technolog, new products, food safety

\section{INTRODUÇ̃̃̃O}

O pescado representa uma importante fonte de proteínas e minerais, além de ácidos graxos poliinsaturados. Apesar de tais características, o consumo de pescado no Brasil é muito baixo em relação ao consumo de outras carnes, o que pode ser explicado pela falta de praticidade em seu preparo e torna imprescindível a busca de novas formas de apresentação, tais como produtos prontos ou semiprontos, pelas indústrias.

No Brasil, a pesca exerce grande importância econômica desde o período colonial (Diegues, 1999). Nessa realidade, no estado do Rio de Janeiro, há a modalidade de pesca conhecida como arrasto, a qual se caracteriza por ser altamente impactante ao ambiente, uma vez que não se mostra seletiva em relação a uma espéciealvo. Por essa falta de seletividade, a produção desembarcada é constituída por diferentes espécies, na qual há tanto aquelas consideradas importantes quanto a "mistura", que se caracteriza por um conjunto de espécies de pouco valor comercial, independentemente de seu tamanho, e ainda há espécies de considerável valor comercial, porém com dimensões muito diminutas, tendo, assim, pouco interesse comercial (Castro, 2000).

Por essa razão, tais espécies acabam sendo devolvidas mortas ao mar, a fim de se ganhar espaço nas embarcações para que espécies de maior interesse possam ser embarcadas (Morais et al., 1995). Com o aumento da exploração dos recursos de pesca e consequente esgotamento dos recursos pesqueiros, é crescente o volume de mistura desembarcado, como forma de se aumentar o rendimento da viagem (Perez et al., 2001).

Atualmente, os resíduos sólidos de pescado têm sido pouco aproveitados e destinados sobretudo à alimentação animal, à fabricação de fertilizantes e de produtos químicos (Cavalcante et al., 2005).

Coelho et al. (1986) analisaram a destinação dada a esse rejeito por empresas pesqueiras nacionais e constataram que $9 \%$ desse resíduo é despejado diretamente em mares e rios. $\mathrm{O}$ pescado, uma considerável fonte de proteínas e sais minerais e ainda a maior reserva de ácidos graxos, principalmente os da série ômega-3 (Trondsen, 2003), tem no Brasil um baixo consumo em relação a outras carnes, o que pode ser justificado não só por problemas na distribuição e comercialização do pescado, mas também pela falta do hábito de consumo, gerado, em parte, pela ausência de praticidade no preparo (Bonacina e Queiroz, 2007). Dados de 2010 colocam o Brasil como um fraco consumidor de pescado, 9,75kg per capita, enquanto a média mundial é de 15kg per capita (Brasil, 2012).

Dessa forma, torna-se de suma importância a busca por novas tecnologias para o uso do pescado, a fim de transformá-lo em produto com maior praticidade e aceitabilidade pela população, como são os produtos prontos ou semiprontos (Bonacina e Queiroz, 2007). 
A rentabilidade comercial da indústria pesqueira está ligada à sua capacidade de mudança e adequação às novas exigências do mercado consumidor, o qual busca novos tipos de produtos que tenham alto valor nutritivo, sejam balanceados e de fácil preparo, diferenciados e menos impactantes (Miranda et al., 2003).

O pescado, quando inserido frequentemente na dieta, auxilia na prevenção de doenças cardiovasculares, no controle da pressão arterial, além de ter importância na lactação e no desenvolvimento neurológico (Avdalov, 2014).

O conceito de segurança alimentar, definido pela "Food and Agriculture Organization" (State..., 2006), consiste em "quando toda pessoa, em todo momento, tem acesso físico e econômico a alimentos suficientes, inócuos e nutritivos para satisfazer suas necessidades alimentares e preferências quanto aos alimentos, a fim de levar uma vida saudável e ativa" (State..., 2006).

Pelo exposto, o objetivo do presente trabalho foi o desenvolvimento de dois produtos à base de pescado, almôndega e quibe, tendo como matéria-prima espécies consideradas resíduos de pesca na modalidade de arrasto, bem como a análise de sua composição centesimal e de suas características físico-químicas, microbiológicas e toxicológicas.

\section{MATERIAL E MÉTODOS}

A coleta dos peixes foi realizada no período da manhã, no cais da Fênix, situado no município de São Gonçalo, Rio de Janeiro. A embarcação de arrasto duplo, Fênix Gonçalense V, teve a saída no dia 10 de janeiro de 2015, às 17 horas, e retornou cinco dias após, às nove horas, exato momento da coleta. Para o período de pesca, a embarcação saiu carregada com 10 mil quilos de gelo. Durante os dias efetivos de pesca, foram realizados 40 lances com duração média de seis horas cada.

Os lances foram feitos nos períodos da manhã, tarde e noite, em profundidade média de 95 metros, usando-se ensacadores com malha de 30 milímetros. $\mathrm{O}$ pesqueiro utilizado foi a localidade Casteliano (latitude $23^{\circ} 45^{\circ}$ /longitude $44^{\circ} 00^{\circ}$ ), em Ilha Grande, Rio de Janeiro. A produção teria como destino o Ceasa do Rio de Janeiro. A coleta das espécies foi feita ao acaso, à medida que o pescado era desembarcado. A identificação taxonômica das espécies seguiu as metodologias propostas por Szpilman (2000) e Figueiredo e Menezes (1978, 1980).

O pescado utilizado como matéria-prima foi acondicionado em gelo até o local de beneficiamento (Escola de Pesca Ascânio de Faria). Os peixes analisados e julgados malconservados, espedaçados ou de aspecto ruim foram descartados.

Nesse local, os peixes foram separados por espécie e, posteriormente, por lotes. Em seguida, foram pesados para posterior avaliação do rendimento.

Os peixes foram lavados, descabeçados, eviscerados e, então, realizou-se a filetagem, seguida de retirada da pele para formulação da massa. O peso final dos filés foi obtido em separado por espécie para a avaliação final de seu rendimento (relação peso total por espécie $\mathrm{x}$ peso dos filés).

Posteriormente, os filés foram misturados e moídos em moedor de carne até a obtenção de uma massa homogênea.

O quibe de peixe foi preparado utilizando-se como ingredientes: $1 \mathrm{~kg}$ de polpa de peixe, $500 \mathrm{~g}$ de farinha de quibe, $25 \mathrm{~g}$ de Tempero Completo Ajinomoto $^{\circledR}, 20 \mathrm{~g}$ de Sopa de Cebola Kodillar ${ }^{\circledR}$, $3 \mathrm{~g}$ de hortelã fresco, $3 \mathrm{~g}$ de salsa e $3 \mathrm{~g}$ de cebolinha.

A almôndega de peixe foi preparada utilizandose como ingredientes: $1 \mathrm{~kg}$ de polpa de peixe, $10 \mathrm{~mL}$ de suco de limão, $10 \mathrm{~g}$ de alho, $5 \mathrm{~g}$ de salsa, $5 \mathrm{~g}$ de cebolinha, $100 \mathrm{~g}$ de cebola e $5 \mathrm{~g}$ de cloreto de sódio.

Para as análises, foram retiradas amostras de $250 \mathrm{~g}$ de cada um dos produtos elaborados: material processado (base dos preparados) e material após cozimento (quibe e almôndega). As amostras foram embaladas a vácuo e congeladas, todas separadas em triplicado para análises e repetições necessárias ao estudo.

As análises foram realizadas nos laboratórios do Centro Estadual de Controle de Pesquisa em Qualidade de Alimentos (CEPQA), localizado na Empresa de Pesquisa Agropecuária do Estado do Rio de Janeiro (Pesagro-RJ). 
Os testes realizados na matéria pré-seca a $105^{\circ} \mathrm{C}$ consistiram em cinzas; proteína bruta (microKjedahl); pH por meio de potenciômetro; temperatura por meio de termômetro de penetração; atividade aquosa (Aw); nitrogênio amoniacal como percentual do nitrogênio total; extrato etéreo com avaliação de lipídeos totais e saturados (método Soxhlet); e teor de sódio e potássio por espectrometria (Antonie et al., 1999). Todas as amostras dos ensaios foram avaliadas em triplicata analítica.

Para a avaliação da inocuidade, foram realizadas, em todas as amostras (polpa crua, quibe e almôndega crus e assados), análises microbiológicas e toxicológicas.

O desenvolvimento microbiológico foi avaliado por meio das análises de contagem total de psicrotróficos em placas, pela técnica do "pourplate": detecção de Salmonella sp.; Staphylococcus sp. e determinações dos números mais prováveis de coliformes termotolerantes e totais, seguindo-se metodologia sugerida pelo Ministério da Agricultura, Pecuária e Abastecimento (Brasil, 2003; Compendium..., 1992).

$\mathrm{Na}$ avaliação toxicológica, analisou-se a presença de gás sulfídrico $\left(\mathrm{H}_{2} \mathrm{~S}\right)$, segundo técnica descrita por Brasil (1981). O teor de histamina foi determinado conforme metodologia espectrofotofluorométrica descrita por Glória e Soares (1993).

\section{RESULTADOS E DISCUSSÃO}

A identificação taxonômica das espécies teve os seguintes resultados: pargo (Pagrus pagrus), castanha (Umbrina sp.), olho-de-cão (Priacanthus arenatus), congro-negro (Conger sp.), congro-rosa (Genypterus brasiliensis) e peixe-sapo (Lophius gastrophysus).

Com base nos dados biométricos, foi obtido um valor total de $25 \mathrm{~kg}$ de peixe, sendo $17,162 \mathrm{~kg}$ $(68,64 \%)$ de pargo; 4,680kg (18,72\%) de castanha; $0,745 \mathrm{~kg} \quad(2,98 \%)$ de olho-de-cão; $1,755 \mathrm{~kg} \quad(7,02 \%)$ de congro-negro; $0,145 \mathrm{~kg}$ $(0,58 \%)$ de congro-rosa e $0,490 \mathrm{~kg}(1,96 \%)$ de peixe-sapo. Todos os peixes estavam inteiros, com exceção do peixe-sapo, que se encontrava sem a cabeça devido ao costume de se descabeçar essa espécie ainda a bordo.
Em estudo conduzido por Duarte et al. (2009), em que foi realizada análise qualitativa $\mathrm{e}$ quantitativa de mistura desembarcada pela frota de arrasto-médio no estado de São Paulo, as famílias Sciaenidae, à qual pertence a Umbrina sp., e Haemulidae tiveram a maior ocorrência; Sciaenidae obteve também o maior percentual em peso. Ao realizar avaliação por espécie, esse mesmo trabalho obteve os maiores valores de frequência, respectivamente, para: Orthopristis ruber, Pagrus pagrus, Priacanthus arenatus, Menticirrhus americanus, Umbrina canosai e Diplectrum formosum.

Ainda segundo Duarte et al. (2009), no outono, $P$. pagrus ocorreu em todas as amostras, com elevado percentual em peso $(26,7 \%)$, e $P$. arenatus teve baixos valores de peso e número, porém esteve presente em todas as amostras dessa estação do ano.

Com relação ao comprimento total para cada espécie, foram obtidos valores médios de: $22,8 \mathrm{~cm}$ para pargo; $24 \mathrm{~cm}$ para castanha; $20,64 \mathrm{~cm}$ para olho-de-cão; $107,5 \mathrm{~cm}$ para congronegro; $32,3 \mathrm{~cm}$ para congro-rosa e $32,9 \mathrm{~cm}$ para peixe-sapo sem cabeça.

Com relação ao peso total para cada espécie, foram obtidos valores médios de: $174,3 \mathrm{~g}$ para pargo; 176g para castanha; 147,6g para olho-decão; $1,755 \mathrm{~kg}$ para congro-negro; $145 \mathrm{~g}$ para congro-rosa e $490 \mathrm{~g}$ para peixe-sapo sem cabeça.

Após a limpeza e filetagem dos peixes, obteve-se o rendimento de filé para cada espécie, conforme ilustrado na Tab. 1.

Após a amostragem do material resfriado $\left(3^{\circ} \mathrm{a}\right.$ $4^{\circ} \mathrm{C}$ ) e processado, procedeu-se à divisão da massa total de peixe, sendo obtidas subamostras de $250 \mathrm{~g}$. Em razão da diversidade de espécies utilizadas e de sua complexidade, foi de suma importância a homogeneização da massa base de pescado (polpa de pescado).

A polpa de pescado, ao ser avaliada, não demonstrava odor característico forte $\mathrm{e}$ apresentou aspecto homogêneo, sem presença de qualquer resíduo sólido que estivesse conferindo risco para o manipulador ou para o consumidor. 
Tabela 1. Rendimento de filé das seis espécies estudadas após limpeza e filetagem

\begin{tabular}{lccc}
\multicolumn{1}{c}{ Espécie } & Peso inicial $(\mathrm{kg})$ & Peso final $(\mathrm{kg})$ & Rendimento do filé $(\%)$ \\
\hline Pargo & 17,162 & 7,232 & 42,13 \\
Castanha & 4,680 & 1,978 & 42,26 \\
Olho-de-cão & 0,745 & 0,244 & 32,75 \\
Congro-negro & 1,755 & 0,264 & 15,04 \\
Congro-rosa & 0,145 & 0,056 & 38,62 \\
Peixe-sapo (sem cabeça) & 0,490 & 0,255 & 52,04 \\
\hline
\end{tabular}

Os valores de $\mathrm{pH}$ da polpa de pescado, bem como dos produtos acabados, variaram na ordem de 6,20 $\pm 0,30$, sendo estes obtidos em dois momentos: ainda resfriados e ao final do processamento.

Os valores de Aw da polpa de pescado ao início do processamento variaram na ordem de $0,90 \pm 0,15$. Ao final do processamento, foram obtidos valores similares, estando estes ainda no intervalo médio de $0,90 \pm 0,15$.

O valor de matéria seca percentual, encontrado na polpa, foi de $31,20 \pm 1,30 \%$. Estudos semelhantes com CMS de pescado lavado relatam teores de 92,78\%. Valores de umidade em CMS lavadas podem diferir muito entre si, dependendo dos tipos de pescado utilizados para formar o material (Simões et al., 1998). Com relação ao quibe e à almôndega crus, os valores encontrados foram de $37,90 \pm 1,10$ e $32,10 \pm 1,10$, respectivamente. Para os produtos assados, os resultados foram $33,40 \pm 1,20$ para o quibe $\mathrm{e}$ $34,20 \pm 1,00$ para a almôndega. Para o preparo do produto, foi realizada pré-hidratação do trigo integral, que permaneceu em remolho (por duas horas). Devido à propriedade higroscópica do trigo, esse grão chega a ganhar de duas a três vezes peso final em relação ao seu peso seco (Philippi, 2006).

Os teores de cinzas encontrados na polpa estão em 1,5\%; resultados similares foram encontrados por Marchi (1997) em polpa de tilápia. As avaliações de sódio e potássio, com base nos teores minerais obtidos neste estudo, consideraram valores percentuais de $1,05 \pm 0,05 \%$ e $16,00 \pm 0,05 \%$, respectivamente. Com relação ao quibe e à almôndega crus, os valores de cinzas

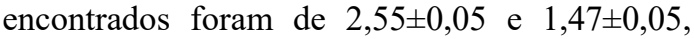
respectivamente. Para os produtos assados, os resultados foram $1,87 \pm 0,05$ para o quibe e $1,92 \pm 0,05$ para a almôndega.
Com base na matéria seca, avaliou-se a quantidade de lipídeos, cujos teores aferidos na polpa foram de $4,80 \pm 0,30 \%$. Com relação ao quibe e à almôndega crus, o percentual de

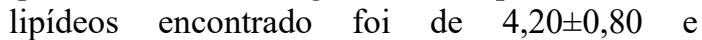
$4,20 \pm 0,60$, respectivamente. Para os produtos

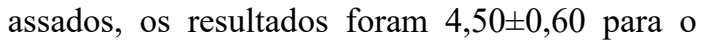
quibe e 4,40 $\pm 0,60$ para a almôndega. Gryscheket et al. (2003) observaram teores de lipídeos de $4,23 \%$ e 1,70\% em CMS de tilápia-do-nilo, não lavada e lavada, respectivamente, o que demonstra que o processamento pode interferir na caracterização do material.

Os lipídeos dos alimentos constituem-se principalmente em triacilglicerídeos, fosfolipídeos e esteróis e ocorrem naturalmente na maioria das matérias-primas utilizadas na indústria de alimentos ou, então, são adicionados como ingredientes funcionais. Como nutrientes, os lipídeos, em especial dos triglicerídeos, constituem uma importante fonte calórica, que fornece ácidos graxos essenciais, e também servem como solvente ou veículo para as vitaminas lipossolúveis entre outros nutrientes (German, 1999).

A implantação de reações químicas nos lipídeos é favorecida principalmente por tratamentos térmicos, que têm importância tecnológica em inúmeras etapas de produção, incluindo seleção da matéria-prima, formas de criação, estocagem, beneficiamento e distribuição (German, 1999).

No presente estudo, a proteína bruta apresentou na polpa um índice de $15,60 \pm 1,04 \%$. Com relação ao quibe e à almôndega crus, os valores

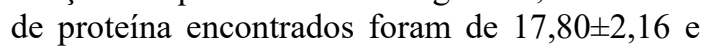
$14,90 \pm 2,12$, respectivamente. Para os produtos assados, os resultados foram $15,10 \pm 2,10$ tanto para o quibe quanto para a almôndega. Bonacina e Queiroz (2007) obtiveram valores de 12,4\% de proteína bruta em empanado de pescado (corvina), pré-frito por 30 segundos, em aproximadamente $180^{\circ} \mathrm{C}$. Por se tratar de um 
grão, é sabido que o macronutriente em maior quantidade é o carboidrato, porém o teor protético deve ser levado em consideração (4:2 partes de carboidrato/proteína), segundo Franco (1999). Além disso, devido à alta quantidade de água no trigo após hidratação, há uma diluição nos teores de macronutrientes (Macritchie, 1992).

Os teores de NNP conferem uma ótima avaliação da ação microbiana sob o material. Considerando-se a ação das proteases sob a polpa, essa medida permite estimar o grau de degradação presente após o processamento. Os compostos nitrogenados solúveis, formadores do NNP, que ocorre durante o processo, apresentaram valores de $285 \mathrm{mg} \mathrm{NNP} / 100 \mathrm{~g}$ de polpa de pescado crua, 291mg NNP/100g no quibe cru, $294 \mathrm{mg} \mathrm{NNP} / 100 \mathrm{~g}$ na almôndega crua, $289 \mathrm{mg} \mathrm{NNP} / 100 \mathrm{~g}$ no quibe assado e $292 \mathrm{mg}$ $\mathrm{NNP} / 100 \mathrm{~g}$ na almôndega assada. Estudos com polpa de tilápia, relatados por Contreras-Guzmán (1994), consideram valores de NNP ao redor de 344mg NNP/100g de músculo de tilápia-do-nilo como valores aceitáveis após o processamento. No presente estudo, constatou-se que o processamento não se mostrou um fator que influencie na qualidade final do material, comprovando-se, por meio deste e de outros dados, que as boas práticas de processamento, quando mantidas, conferem uma boa qualidade final ao produto. Todos os resultados apresentados encontram-se expostos nas Tab. 2 e 3.

Tabela 2. Composição centesimal da Polpa de Pescado e Produtos Processados

\begin{tabular}{|c|c|c|c|c|}
\hline Amostras (*) & Matéria seca (\%) & Proteína bruta $(\%)$ & Lipídeos (\%) & Cinzas $(\%)$ \\
\hline Polpa de pescado cru & $31,20 \pm 1,30$ & $15,60 \pm 1,04$ & $4,80 \pm 0,30$ & $1,35 \pm 0,04$ \\
\hline Quibe de polpa de pescado cru & $37,90 \pm 1,10$ & $17,80 \pm 2,16$ & $4,20 \pm 0,80$ & $2,55 \pm 0,05$ \\
\hline $\begin{array}{l}\text { Almôndega de polpa de } \\
\text { pescado cru }\end{array}$ & $32,10 \pm 1,10$ & $14,90 \pm 2,12$ & $4,20 \pm 0,60$ & $1,47 \pm 0,05$ \\
\hline $\begin{array}{l}\text { Quibe de polpa de pescado } \\
\text { assado }\end{array}$ & $33,40 \pm 1,20$ & $15,10 \pm 2,10$ & $4,50 \pm 0,60$ & $1,87 \pm 0,05$ \\
\hline $\begin{array}{l}\text { Almôndega de polpa de } \\
\text { pescado assada }\end{array}$ & $34,20 \pm 1,00$ & $15,10 \pm 2,10$ & $4,40 \pm 0,60$ & $1,92 \pm 0,05$ \\
\hline
\end{tabular}

(*)Médias $(\mathrm{n}=3)$ de análises em triplicata.

Tabela 3. Níveis de sódio $(\mathrm{Na})$ e potássio $(\mathrm{K})$ da polpa de pescado e de produtos processados

\begin{tabular}{lcccc}
\hline \multicolumn{1}{c}{ Amostras $\left(^{*}\right)$} & $\mathrm{Na}(\%)$ & $\mathrm{Na}(\mathrm{mg} / 100 \mathrm{~g})$ & $\mathrm{K}(\%)$ & $\mathrm{K}(\mathrm{mg} / 100 \mathrm{~g})$ \\
\hline Polpa de pescado cru & $1,05 \pm 0,05$ & $30,20 \pm 0,50$ & $16,00 \pm 0,05$ & $235 \pm 0,50$ \\
Quibe de polpa de pescado cru & $1,15 \pm 0,05$ & $36,70 \pm 0,50$ & $17,50 \pm 0,05$ & $255 \pm 0,05$ \\
Almôndega de polpa de pescado cru & $1,17 \pm 0,05$ & $32,10 \pm 0,50$ & $15,70 \pm 0,05$ & $247 \pm 0,05$ \\
& $1,17 \pm 0,05$ & $32,10 \pm 0,50$ & $15,70 \pm 0,05$ & $247 \pm 0,05$ \\
$\begin{array}{l}\text { Quibe de polpa de pescado assado } \\
\begin{array}{l}\text { Almôndega de polpa de pescado } \\
\text { assada }\end{array}\end{array}$ & $1,17 \pm 0,05$ & $32,10 \pm 0,50$ & $15,70 \pm 0,05$ & $247 \pm 0,05$ \\
\hline
\end{tabular}

(*)Médias $(\mathrm{n}=3)$ de análises em triplicata.

Com relação aos teores de sódio, os produtos finais obtiveram baixos teores de sódio, tendo como valor médio a quantidade de $32,10 \mathrm{mg}$ para cada $100 \mathrm{~g}$ de amostra. Segundo a Organização Mundial de Saúde (OMS), o consumo diário recomendado de sal é de $5 \mathrm{~g}$ por dia. De acordo com a Sociedade Brasileira de Cardiologia (Dia..., 2015), no Brasil esse consumo é de $12 \mathrm{~g}$ per capita ao dia e, se fossem seguidos os padrões recomendados pela OMS, haveria uma redução de $15 \%$ nas mortes por acidentes vasculares e de $10 \%$ nos episódios de infarto.
Ainda segundo a SBC, 1,5 milhão de indivíduos hipertensos, por meio da diminuição do consumo de sódio, deixariam de ter que fazer uso de antihipertensivos bem como poderiam ter sua expectativa de vida elevada em mais de quatro anos (Dia..., 2015).

A contagem total de psicrotróficos permaneceu com valores semelhantes, tanto no material processado quanto na polpa base. Contagens de psicrotróficos iniciais mais elevadas foram reportadas por Marchi (1997), que demonstrou a 
necessidade dessa avaliação. Devido ao fato de o grupo apresentar potencial de transmissão de doenças por alimentos (DTS), é preciso que se faça revisão da legislação pertinente ao tema, no que diz referência à $\mathrm{RDC} \mathrm{n}^{\circ} 12$, publicada pela Anvisa (Brasil, 2001), o que reforça a importância da revisão dos parâmetros de inocuidade dos alimentos.

Os resultados da contagem total de psicrotróficos observados no presente estudo (Tab. 4) mantiveram-se abaixo do limite permitido pela Apha (Compendium..., 1992), que é de log $7,0 \mathrm{UFC} / \mathrm{g}$, para contagem padrão em placas de microrganismos aeróbicos. Não foi constatada a presença de coliformes fecais Salmonella e Staphylococcus aureus durante o período de estocagem, que esteve dentro dos padrões estabelecidos pela legislação brasileira (Brasil, 2001).

Tabela 4. Contagem total de psicrotróficos (log UFC/g) da polpa de pescado e de produtos processados

\begin{tabular}{lcc}
\hline \multicolumn{1}{c}{ Amostras $\left(^{*}\right)$} & Inicial & Estocagem 30 dias \\
\hline Polpa de pescado cru & $0,47 \times 10^{1} \pm 0,1 \times 10^{1}$ & $0,54 \times 10^{1} \pm 0,4 \times 10^{1}$ \\
Quibe de polpa de pescado cru & $0,91 \times 10^{1} \pm 0,2 \times 10^{1}$ & $2,92 \times 10^{1} \pm 0,2 \times 10^{1}$ \\
Almôndega de polpa de pescado cru & $1,26 \times 10^{1} \pm 0,4 \times 10^{1}$ & $3,44 \times 10^{1} \pm 0,4 \times 10^{1}$ \\
Quibe de polpa de pescado assado & $0,51 \times 10^{1} \pm 0,4 \times 10^{1}$ & $1,14 \times 10^{1} \pm 0,4 \times 10^{1}$ \\
Almôndega de polpa de pescado assada & $0,54 \times 10^{1} \pm 0,4 \times 10^{1}$ & $1,15 \times 10^{1} \pm 0,4 \times 10^{1}$ \\
\hline
\end{tabular}

(*)Médias $(\mathrm{n}=3)$ de análises em triplicata.

Complementar a essas análises, foram avaliados os teores de histamina e de compostos à base de enxofre em todas as amostras, e não se detectaram níveis desses compostos pelas metodologias propostas. Considerando-se o período de estocagem, pode-se concluir que o produto se encontra dentro dos padrões estabelecidos pela legislação brasileira (Brasil, 2011).

Por se utilizar de uma matéria-prima (polpa de pescado) que pode ter sua origem em variadas espécies e proporções, tais produtos à base de mistura de arrasto tornam-se de dificultosa padronização no que diz respeito aos seus índices nutricionais. Propostas futuras que desenvolvam alimentos e tecnologias que possam padronizar produtos à base de polpa de pescado, sem que ocorram perdas das características funcionais e nutricionais, são importantes para o aproveitamento adequado desse rejeito de pesca.

\section{CONCLUSÕES}

A utilização da polpa de pescado demonstrou viabilidade nos pontos tecnológico e nutricional, $\mathrm{e}$, por conseguinte, revela a possiblidade de seu aproveitamento para elaboração de produtos. Novas formas de apresentação e aproveitamento, tais como produtos prontos ou semiprontos, permitem agregar praticidade ao seu preparo, o que iria favorecer o consumo de produtos à base de pescado. A busca por um alimento nutritivo e inócuo é reforçada pela aplicação de boas práticas de fabricação durante a elaboração de alimentos, em especial pescados, a fim de manter a qualidade dos produtos. Produtos de manipulação que agreguem valor à polpa de pescado permitem que, após o processamento tecnológico adequado, possam ser obtidos produtos que mantenham índices nutricionais $\mathrm{e}$ sanitários adequados.

\section{REFERÊNCIAS}

ANTONIE, F.R.; WEI, C.I.; LITTELL, R.C. HPLC method for analysis of free amino acids in fish using o-phthaldialdehyde pre column derivatization. J. Sci. Food Agric., v.47, p.51005107, 1999.

AVDALOV, N.N. Beneficios del consumo de pescado.Montevideo: Dirección Nacional de Recursos Acuáticos, 2014. 30p.

BONACINA, M.; QUEIROZ, M.I. Elaboração de empanado a partir da corvina (Micropogonias furnieri). Food Sci. Technol., v.27, p.544-552, 2007.

BRASIL. Ministério da Agricultura, Pecuária e Abastecimento. Secretaria Nacional de Defesa Agropecuária. Instrução Normativa $n^{\circ}$. 62, de 26 de agosto de 2003. Oficializa os Métodos Analíticos Oficiais para Análises Microbiológicas para Controle de Produtos de Origem Animal e Água. Diário Oficial da União, Brasília, 18 set. 2003. Seção 1, pág. 14. 
BRASIL. Ministério da Agricultura, Pecuária e Abastecimento. Secretaria Nacional de Defesa Agropecuária. Instrução Normativa $n^{\circ} .25$, de 02 de junho de 2011. Aprovar os Métodos Analíticos Oficiais Físico-químicos para Controle de Pescado e seus Derivados, na forma do Anexo à presente Instrução Normativa. Diário Oficial da União, Brasília, 03 jun. 2011. Seção 1, pág. 12.

BRASIL. Ministério da Pesca e Aquicultura. Boletim estatístico da pesca e aquicultura 2010. Brasília, 2012. 129p.

BRASIL. Ministério da Saúde. Agência Nacional de Vigilância Sanitária. Resolução RDC $n^{\circ}$. 12, de 02 de janeiro de 2001. Aprovar o Regulamento Técnico Sobre Padrões Microbiológicos para Alimentos, em Anexo. Diário Oficial da União, Brasília, 10 jan. 2001. Seção 1.

BRASIL. Ministério da Agricultura. Secretaria Nacional de Defesa Animal. Portaria $\mathrm{n}^{\circ}$. 01, de 07 de outubro de 1981. Aprova os métodos analíticos para controle de produtos de origem animal e seus ingredientes. Diário Oficial da União, Brasília, 13 out. 1981.

CASTRO, P.M.G. Estrutura e dinâmica da frota de parelhas do Estado de São Paulo e aspectos biológicos dos principais recursos pesqueiros demersais costeiros da região sudeste/sul do

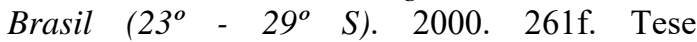
(Doutorado) - Universidade de São Paulo, São Paulo, SP.

CAVALCANTE JÚNIOR, V.; ANDRADE, L.N.; BEZERRA, L.N. et al. Reuso de água em um sistema integrado com peixes, sedimentação, ostras e macroalgas. Rev. Bras. Eng. Agríc. Ambien., v.9, p.118-122, 2005.

COELHO, J.A.P.; PUZZI, A.; GRAÇA-LOPES, R. et al. Análise da rejeição de peixes na pesca artesanal dirigida ao camarão sete-barbas (Xiphopenaeus kroyeri) no litoral do Estado de São Paulo. Bol. Inst. Pesca, v.13, p.51-61, 1986.

COMPENDIUM of methods for the microbiological examination of foods. 3.ed. Washington: APHA, 1992. 1219p.

CONTRERAS-GUZMÁN, E.S. Bioquímica de pescados e invertebrados. Jaboticabal: Fundação Universidade Estadual Paulista, 1994. 409p.
DIEGUES, A.C. A sócio-antropologia das comunidades de pescadores marítimos no Brasil. Etnográfica, v.3, p.361-375, 1999.

DUARTE, G.Q.; SOUZA, M.R.; CARNEIRO, M.H.; SERVO, G.J.M. Composição qualiquantitativa da categoria "mistura" na pesca de arrasto duplo de portas médio desembarcada nos municípios de Santos e Guarujá, São Paulo, Brasil. Bol. Inst. Pesca, v.35, p.461-474, 2009.

FIGUEIREDO, J.L.; MENEZES, N.A. Manual de peixes marinhos do sudeste do Brasil. III. Teleostei (2). São Paulo: Museu de Zoologia da Universidade de São Paulo. 1980. 90p.

FIGUEIREDO, J.L; MENEZES, N.A. Manual de peixes marinhos do sudeste do Brasil. II. Teleostei (1). São Paulo: Museu de Zoologia da Universidade de São Paulo. 1978. 110p.

FRANCO, G. Tabela de composição química dos alimentos. 9.ed. Rio de Janeiro: Atheneu, 1999. 194p.

GERMAN, B.J. Food processing and lipid oxidation. Adv. Exp. Med. Biol., v.459, p.23-50, 1999.

GLÓRIA, M.B.A.; SOARES, V.F.M. Comparison of fluorometric methods for the determination of histamine in fish. Arq. Biol. Tecnol., v.36, p.229-235, 1993.

GRYSCHEK, S.F.B.; OETTERER, M.; GALLO, C.R. Characterization and frozen storange stability of minced Nile Tilapia (Oreochromis niloticus) and red tilapia (Oreochromis spp.). J. Aquatic. Food Prod. Techol., v.12, p.57-69, 2003.

MACRITCHIE, F. Physicochemical properties of wheat proteins in relation to functionality. Adv. Food Nutr. Res., v.36, p.1-87, 1992.

MARCHI, J.F. Desenvolvimento e avaliação de produtos à base de polpa e surimi produzidos a partir de tilápia Nilótica, Oreochromis niloticus. 1997. 85f. Dissertação (Mestrado em Ciência e Tecnologia de Alimentos) - Universidade Federal de Viçosa, Viçosa, MG.

MIRANDA, F.F.; PORTO, M.R.A.; PACHECO, R.S.; HERNÁNDEZ-PRENTICE, C. Processo tecnológico destinado à obtenção de flocos de corvina (Micropogon furnieri). In: CONGRESSO DE INICIAÇÃO CIENTÍFICA, 12., 2003. Pelotas. Anais... Pelotas: Universidade Federal de Pelotas, 2003. CD Rom. 
MORAIS, C.; VALENTINI, H.; ALMEIDA, L.A.S.; COELHO, J.A.P. Considerações sobre a pesca e aproveitamento industrial da ictiofauna acompanhante da captura do camarão-setebarbas, na costa sudeste do Brasil. Bol. Inst. Pesca, v.22, p.103-114, 1995.

PEREZ, J.A.A.; PEZZUTO, P.R.; RODRIGUES, L.F. et al. Relatório da reunião técnica de ordenamento da pesca de arrasto nas regiões sudeste e sul do Brasil. Notas Téc. Facimar, n.5, p.1-34, 2001.

PHILIPPI, S.T. Nutrição e dietética. Barueri, SP: Manole, 2006. 424p.

SIMÕES, D.R.S.; PEDROSO, M.A.; RUIZ, W.A.; ALMEIDA, T.L. Hambúrgueres formulados com base protéica de pescado. Food Sci. Technol., v.18, p.414-420, 1998.
DIA Nacional de Prevenção e Combate à Hipertensão Arterial. [São Paulo]: Sociedade Brasileira de Cardiologia. Disponível em: $<$ http://prevencao.cardiol.br/campanhas/hipertens ao.asp>. Acessado em: 4 nov. 2015.

STATE of Food Insecurity in the World 2006 Eradicating world hunger - taking stock ten years after World Food Summit. Roma: FAO, 2006.

SZPILMAN, M. Peixes marinhos do Brasil (guia prático de identificação). Rio de Janeiro: Instituto Ecológico Aqualung, 2000. 288p.

TRONDSEN, T. Perceived barriers to consumption of fish among Norwegian women. Appetite, v.41, p.301-314, 2003. 